\title{
Role of Integrated Pulmonary Index in Identifying Extubation Failure
}

\author{
Ramandeep Kaur MSc RRT-ACCS, David L Vines MHS RRT, Li Liu PhD, and \\ Robert A Balk MD
}

\begin{abstract}
BACKGROUND: The integrated pulmonary index (IPI) utilizes an algorithm based on the measurement of end-tidal carbon dioxide, breathing frequency, heart rate, and oxygen saturation to provide an assessment of the patient's ventilatory status. This clinical trial was designed to determine whether lower IPI values were associated with extubation failure. METHODS: This prospective observational trial was conducted in an academic medical center. After institutional review board approval, 100 mechanically ventilated subjects were enrolled. A stand-alone respiratory monitor that measures IPI was placed on subjects before starting a spontaneous breathing trial and continued for up to $48 \mathrm{~h}$ postextubation. Clinicians were blinded, and data were recorded continuously. Extubation failure was defined as the need for positive-pressure ventilation within $48 \mathrm{~h}$ after extubation. Mixed-effects regression models were employed to examine differences in IPI patterns between subjects with extubation success or failure. Significant IPI changes from baseline were then evaluated to predict extubation outcome. RESULTS: IPI was successfully recorded on 62 subjects (48 successful and 14 failed extubations). Although mean IPI $5 \mathrm{~min}$ before and after extubation were not significantly different, mean IPI $1 \mathrm{~h}$ after extubation in the failure group was significantly lower by $1.19(P=.044)$ compared with the successful group. Negative change in IPI $1 \mathrm{~h}$ after extubation increased odds of failure (odds ratio $=1.57,95 \%$ CI 1.001-2.454). The last mean IPI recorded after extubation was also significantly lower in the failure group compared with the successful group by $3.03(P<.001)$. Negative change in the last measured IPI increased odds of failure (odds ratio $=1.72,95 \%$ CI 1.26-2.34). CONCLUSIONS: Declining IPI measurements postextubation are predictive of extubation failure. Further clinical trials are needed to assess the role of IPI in guiding interventions in extubated patients. Key words: mechanical ventilation; extubation failure; integrated pulmonary index; extubation outcome. [Respir Care 2017;62(12):1550-1556. (C 2017 Daedalus Enterprises]
\end{abstract}

\section{Introduction}

Extubation failure occurs in $10-20 \%$ of extubated patients and is linked with extremely poor outcomes and

\footnotetext{
Ms Kaur, Mr Vines, and Dr Balk are affiliated with the Division of Respiratory Care, Rush University Medical Center, Chicago, Illinois. Dr $\mathrm{Li}$ is affiliated with the Division of Epidemiology and Biostatistics, University of Illinois at Chicago School of Public Health, Chicago, Illinois.

This study was partially funded by a grant from Oridion Capnography. $\mathrm{Mr}$ Vines has disclosed a relationship with Medtronic-Covidien, which owns Oridion Capnography. The other authors have disclosed no conflicts of interest.
}

Ms Kaur presented a previous version of this work at the American Thoracic Society 2016, held May 13-18, in San Francisco, California. high mortality rate. ${ }^{1,2}$ Extubation failure may result from a number of factors, such as impaired respiratory center drive, neuromuscular abnormalities, underlying disease severity, ineffective cough, increased pulmonary secretions, and/or impaired lung mechanics. Predictive indexes for extubation outcomes are frequently inaccurate. ${ }^{3,4}$ Unlike weaning outcome, which is measured by rapid shallow breathing index to determine a patient's success, there is no standard index or tool available to assess the extubation outcome. ${ }^{4}$

\footnotetext{
Correspondence: Ramandeep Kaur MSc RRT-ACCS, Rush University Medical Center, Department of Respiratory Care, 1202 Lower Level Tower, 1620 W Harrison Street, Chicago, IL 60612. E-mail: ramandeep_kaur@rush.edu.
}

DOI: $10.4187 /$ respcare. 05434 


\section{IDENTIFYING EXTUBATION FAILURE WITH IPI}

Among patients who pass a spontaneous breathing trial (SBT), approximately $15-18 \%$ fail extubation..$^{5-7}$ Most of the parameters that are available to measure respiratory mechanics play a minimal role in predicting extubation outcome. ${ }^{8,9}$

The FDA-cleared integrated pulmonary index (IPI) algorithm utilizes the real-time measurement and interactions of 4 parameters (end-tidal carbon dioxide $\left[\mathrm{P}_{\mathrm{ETCO}_{2}}\right]$, breathing frequency, heart rate, and $\mathrm{S}_{\mathrm{pO}_{2}}$ ) to provide a rapid assessment of a patient's respiratory status. The algorithm is designed to calculate IPI from various combinations of these measured parameters using a fuzzy logic model that mimics human thinking and associated clinical decision making based on a group of clinical experts. ${ }^{10}$ IPI is displayed as a single indexed value from 1 to 10 . In a clinical validation study by Ronen et al, ${ }^{10}$ an IPI $\leq 4$ was thought to require immediate clinical intervention due to deterioration in the patient's respiratory status.

Currently, no published data exist assessing IPI's association with weaning or extubation outcomes of mechanically ventilated patients. The aim of this prospective observational study was to determine whether IPI values differed significantly for subjects who were successfully extubated compared with those who failed extubation.

\section{Methods}

\section{Subjects}

This study was approved by the Rush University Medical Center institutional review board (approval number 10090811) as part of a multi-center trial. A waiver of informed consent was obtained for this observational trial, since there was no more than minimal risk involved. We were the only institution collecting postextubation data. From March 2011 to January 2015, all patients admitted to the ICUs requiring mechanical ventilation and who met the inclusion criteria and did not meet the exclusion criteria were enrolled in the study. Enrollment was stratified based on the length of mechanical ventilation such that not more than $20 \%$ subjects were enrolled in the $<24$-h group, not more than $40 \%$ were in the $24-48$-h group, not more than $40 \%$ were in the $48-72$-h group, and not more than $30 \%$ were in the $>72-\mathrm{h}$ group. This study excluded patients who were ventilated noninvasively or via tracheostomy. Once the potential study subject was identified, he or she was connected to the bedside Oridion CS20 monitor (Medtronic) with the IPI algorithm. The monitor's pulse oximeter probe was attached to the subject, and the capnography $\left(\mathrm{CO}_{2}\right)$ sampling filter line (Medtronic) was placed at the ventilator circuit Y-piece and connected to the closed suctioning system or endotracheal tube. The study subject was admitted to the CS20 monitor with a de-identified identification number, and continuous data were recorded

\section{QUICK LOOK}

\section{Current knowledge}

Extubation failure occurs in about $20-25 \%$ mechanically ventilated patients and is associated with poor outcomes in terms of length of hospital stay, morbidity and mortality. Currently, there is no standard tool/index to accurately predict the extubation outcome.

\section{What this paper contributes to our knowledge}

In this prospective observational study, decrease trend of integrated pulmonary index after extubation provided an indication of impending respiratory failure. This decline in IPI over time can be utilized to identify patients who are at risk of developing postextubation respiratory failure.

to a USB drive. Before beginning the SBT, baseline data were collected for $10 \mathrm{~min}$. Once the baseline data were collected, the SBT was performed, and data were recorded to the thumb drive. Based on the institution policy, SBT was conducted for 30 min using automatic tube compensation with a PEEP of $5 \mathrm{~cm} \mathrm{H}_{2} \mathrm{O}$ on all study subjects. If the subject did not pass the SBT, the same steps were followed for subsequent daily SBTs but not to exceed 3 trials. Monitoring was stopped in subjects who failed 3 daily consecutive SBT trials. All extubated subjects were placed on a Smart Capnoline Oxygen cannula (Medtronic) to provide oxygen and monitor $\mathrm{P}_{\mathrm{ETCO}_{2}}$ noninvasively and were followed up for $48 \mathrm{~h}$ postextubation.

\section{Definition of Variables}

The primary outcome measurement was extubation outcome or the ability to maintain spontaneous, unassisted breathing at $48 \mathrm{~h}$ after discontinuation of mechanical ventilation. The subject was considered an extubation failure if: (1) the subject was re-intubated and returned to mechanical ventilation within $48 \mathrm{~h}$ after the initial discontinuation from the ventilation or (2) if the subject required continuous noninvasive ventilation (NIV) within $48 \mathrm{~h}$ after initial discontinuation from the ventilation. Successful extubation was defined as freedom from positive-pressure ventilation at $48 \mathrm{~h}$ postextubation.

\section{Data Collection}

For each enrolled subject, demographics, admitting diagnosis, co-morbidities, reason for intubation/mechanical ventilation, and the name of the surgical procedure if intubated in the operating room was collected to describe 


\section{IDENTIFYING EXTUBATION FAILURE WITH IPI}

subject groups. The timing and date of initiation of mechanical ventilation, ventilator settings, and arterial blood gas before first SBT, endotracheal tube size, and the specific critical care unit where the subject was admitted was recorded. After completion of each SBT, the following data were collected: date, SBT start time, SBT end time, SBT outcome, reasons if passed SBT but not extubated, reasons for failed SBT, rapid shallow breathing index at start of SBT, and rapid shallow breathing index at end of SBT. For extubation, the date and time of extubation and oxygen therapy used postextubation was recorded. After extubation, the following information was recorded: time subject remained without mechanical ventilation, use of rescue NIV, NIV settings, re-intubation date and time within $48 \mathrm{~h}$ postextubation, and the reason for NIV or re-intubation. If the subject required rescue NIV postextubation, IPI recording was stopped. After all of the data collection, IPI data were then consolidated and recorded on an Excel (Microsoft, Redmond, Washington) spreadsheet for statistical analysis.

\section{Statistical Analysis}

Data were uploaded onto an FTP site at Oridion for the data to be compressed into 1-min usable averages. We manually identified the last measured IPI in all the subjects analyzed in this study. Mixed-effects regression models were employed to compare the over time patterns in 4 repeated measures of IPI (baseline [ie, 5 min before extubation], $5 \mathrm{~min}$ after, $1 \mathrm{~h}$ after, and last IPI), between subjects who were successfully extubated and those who failed extubation. Likelihood ratio tests and fit statistics, such as Akaike information criterion and Bayesian information criterion, were used to select the best-fit variance-covariance structure for the repeated measurements. A backward selection method was employed to select demographic variables that could potentially affect IPI. Measurement time was treated as a categorical variable, with baseline as reference, to identify the time point at which group IPI difference occurred. Interactions between group (extubation failure vs success) and measurement time points were included in the model to allow and estimate the difference in the patterns of change between groups. The repeatedly measured IPI values were modeled using PROC MIXED in SAS (SAS Institute, Cary, North Carolina). Once the time points of significant group differences in IPI were identified, IPI changes from baseline were used in the logistic regression model predicting extubation outcome (PROC LOGISTIC in SAS). Backward selections were performed to identify factors associated with extubation outcome. Estimates and 95\% CIs for odds ratios were reported for significant factors. All tests were 2-sided hypothesis tests, controlling for type-1 error probability of 0.05 .

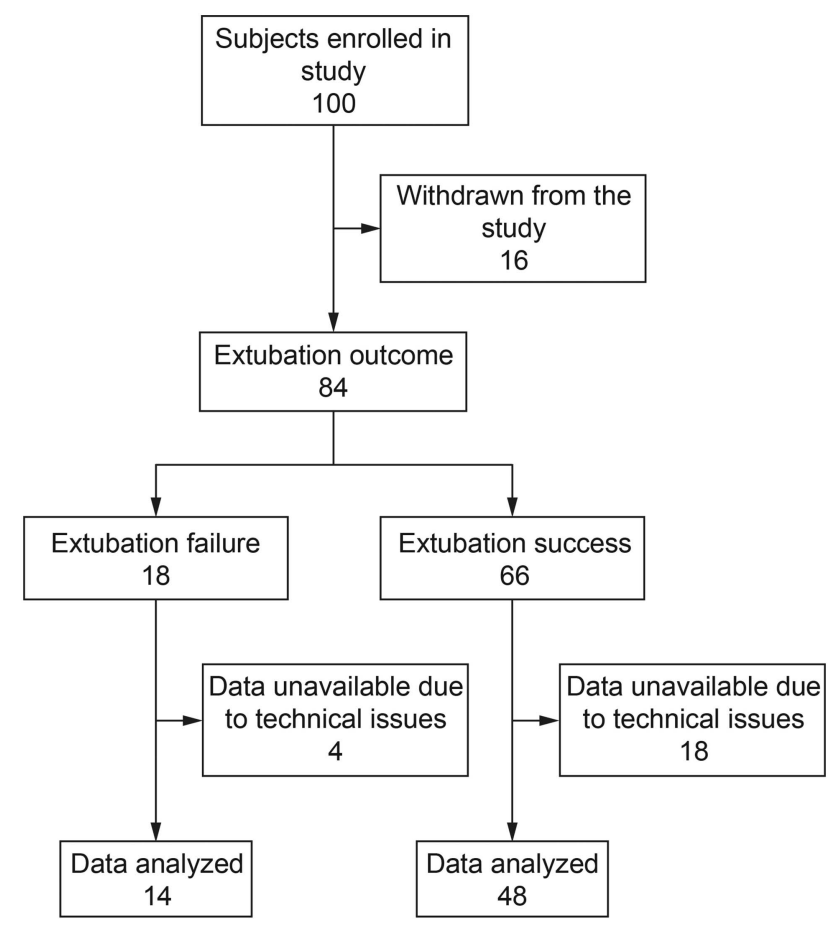

Fig. 1. Flow chart.

\section{Results}

One hundred subjects met the inclusion criteria and were enrolled in the trial, but 16 were withdrawn from the study due to inability to liberate from mechanical ventilation. Of those included, 66 subjects were successfully extubated, and 18 failed extubation. Due to the inability to compress data on 22 subjects, only 48 were included in the successful extubation group and 14 in the failed extubation group (Fig. 1). Of 14 who failed extubation, 9 were re-intubated and required mechanical ventilation, whereas 5 were placed on NIV.

Overall subject characteristics are shown in Table 1. Mean age was about $63 \mathrm{y}$. Males represented $43.5 \%$ and females $56.5 \%$ of all subjects included. Approximately half of the study population was white $(51.6 \%), 17$ subjects $(27.4 \%)$ were African-American, and most of the sample was overweight (mean body mass index, $29.39 \pm 8.07$ ). The primary reason for intubation was respiratory failure $(48.4 \%)$ followed by postoperative issues $(38.7 \%)$, cardiac issues $(6.5 \%)$, and airway protection $(4.8 \%)$. The baseline arterial blood gas values before first SBT were within normal limits among all study participants.

Sample characteristics by extubation outcomes are also shown in Table 1. Of the 62 study participants, 48 (77.4\%) were successfully extubated, and $14(22.6 \%)$ required either re-intubation or NIV within $48 \mathrm{~h}$ after the initial discontinuation of mechanical ventilation. Subject char- 
Table 1. Subject Characteristics

\begin{tabular}{|c|c|c|c|c|}
\hline Characteristics & Overall $(N=62)$ & Extubation Success $(n=48)$ & Extubation Failure $(n=14)$ & $P$ \\
\hline Age, mean $\pm \mathrm{SD}$ y & $63.4 \pm 13.6$ & $63.9 \pm 12.2$ & $63.5 \pm 17.8$ & .14 \\
\hline Male/female sex, $n(\%)$ & $27(43.5) / 35(56.5)$ & $22(45.8) / 26(54.2)$ & $5(36) / 9(64)$ & .36 \\
\hline $\mathrm{BMI}$, mean $\pm \mathrm{SD} \mathrm{kg} / \mathrm{m}^{2}$ & $29.39 \pm 8.07$ & $29.39 \pm 6.67$ & $31.49 \pm 8.87$ & .13 \\
\hline Ethnicity, $n(\%)$ & & & & .14 \\
\hline Caucasian & $32(51.6)$ & $26(54.2)$ & $6(42.9)$ & \\
\hline African-American & $17(27.4)$ & $10(20.8)$ & $7(50)$ & \\
\hline Asian & $3(4.8)$ & $3(6.3)$ & 0 & \\
\hline Hispanic & $10(16.1)$ & $9(18.8)$ & $1(7.1)$ & \\
\hline Reason for intubation, $n(\%)$ & & & & .95 \\
\hline Respiratory failure & $30(48.4)$ & $24(50)$ & $6(42.9)$ & \\
\hline Postoperative & $24(38.7)$ & $18(37.5)$ & $6(42.9)$ & \\
\hline Airway protection & $3(4.8)$ & $2(4.2)$ & $1(7.1)$ & \\
\hline Cardiac issues & $4(6.5)$ & $3(6.3)$ & $1(7.1)$ & \\
\hline Others & $1(1.6)$ & $1(2.1)$ & 0 & \\
\hline \multicolumn{5}{|l|}{$\mathrm{ABG}$ before first $\mathrm{SBT}$, mean $\pm \mathrm{SD}$} \\
\hline Arterial $\mathrm{pH}$ & $7.42 \pm 0.06$ & $7.42 \pm 0.62$ & $7.46 \pm 0.34$ & .036 \\
\hline $\mathrm{P}_{\mathrm{aCO}_{2}}, \mathrm{~mm} \mathrm{Hg}$ & $37.24 \pm 9.37$ & $37.40 \pm 8.60$ & $36.69 \pm 12.18$ & .81 \\
\hline $\mathrm{P}_{\mathrm{aO}_{2}}, \mathrm{~mm} \mathrm{Hg}$ & $131.72 \pm 64.85$ & $138.15 \pm 69.22$ & $108 \pm 38.52$ & .13 \\
\hline $\mathrm{HCO}_{3}^{-}, \mathrm{mEq} / \mathrm{L}$ & $23.95 \pm 5.77$ & $23.51 \pm 4.84$ & $25.58 \pm 8.44$ & .25 \\
\hline $\mathrm{S}_{\mathrm{aO}_{2}}, \%$ & $97.58 \pm 2.38$ & $97.84 \pm 1.79$ & $96.7 \pm 3.80$ & .11 \\
\hline Duration of mechanical ventilation, $n(\%)$ & & & & .48 \\
\hline$<24 \mathrm{~h}$ & $18(29)$ & $15(31.3)$ & $3(21.4)$ & \\
\hline $24-48 \mathrm{~h}$ & $17(27.4)$ & $14(29.2)$ & $3(21.4)$ & \\
\hline $48-72 \mathrm{~h}$ & $13(21)$ & $8(16.7)$ & $5(35.7)$ & \\
\hline$>72 \mathrm{~h}$ & $14(22.6)$ & $11(22.9)$ & $3(21.4)$ & \\
\hline $\begin{array}{l}\mathrm{BMI}=\text { body mass index } \\
\mathrm{ABG}=\text { arterial blood gas } \\
\mathrm{SBT}=\text { spontaneous breathing trial } \\
\mathrm{mEq}=\text { milliequivalents }\end{array}$ & & & & \\
\hline
\end{tabular}

acteristics were similar in both groups in terms of age, sex, body mass index, ethnicity, reason for initiating mechanical ventilation, and length of mechanical ventilation. However, as compared with those who successfully passed extubation, subjects who failed extubation had a significantly higher $\mathrm{pH}$ before initiation of the first $\operatorname{SBT}(P=.036)$.

Mean IPI over time for the 2 groups (extubation failure or success) is plotted in Fig. 2. Whereas IPI measures remained relatively stable for subjects who successfully extubated, IPI means decreased for those who failed extubation. Likelihood ratio tests and fit statistics suggested that an unstructured variance-covariance pattern fit the data the best. Fixed-effects parameter estimates from the selected model with the unstructured pattern are shown in Table 2. Results indicated that IPI in the success group remained around 7.3-7.8 with no statistical difference. Whereas estimated IPIs in the failure group were not statistically different from those of the success group at baseline or $5 \mathrm{~min}$ after extubation, the failure group IPI was significantly lower by 1.19 at $1 \mathrm{~h}$ after and even more so at the last measurement, by 3.03. The overall time point by group interaction was highly significant $(P<.001)$.

Based on the identified group IPI difference starting from the third IPI measurement ( $1 \mathrm{~h}$ after extubation), we created 2 IPI change-from-baseline variables. IPI3 - 1 represents the third IPI measure $(1 \mathrm{~h}$ after $)$ minus baseline IPI, and IPI $4-1$ is the last IPI measure minus baseline IPI. Results from backward selection from all demographic variables in the logistic regression models predicting extubation outcome are shown in Table 3. Model results revealed that African-American subjects were less likely to be successfully extubated than the rest of the population (odds ratio $=0.20$, 95\% CI 0.04-0.93). After adjustment for AfricanAmerican race, both IPI change-from-baseline variables (IPI3 - 1 [Table 3, top] and IPI4 - 1 [Table 3, bottom]) were significantly associated with the extubation outcome. The positive effects of IPI changes on the outcome (IPI3 -1 estimate $=0.45, P=.050$; IPI4 -1 estimate $=0.54, P<.001)$ revealed that increases in later IPI measures ( $1 \mathrm{~h}$ after and last measurement) resulted in higher odds of having a successful extuba- 


\section{IDENTIFYING EXTUBATION FAILURE WITH IPI}

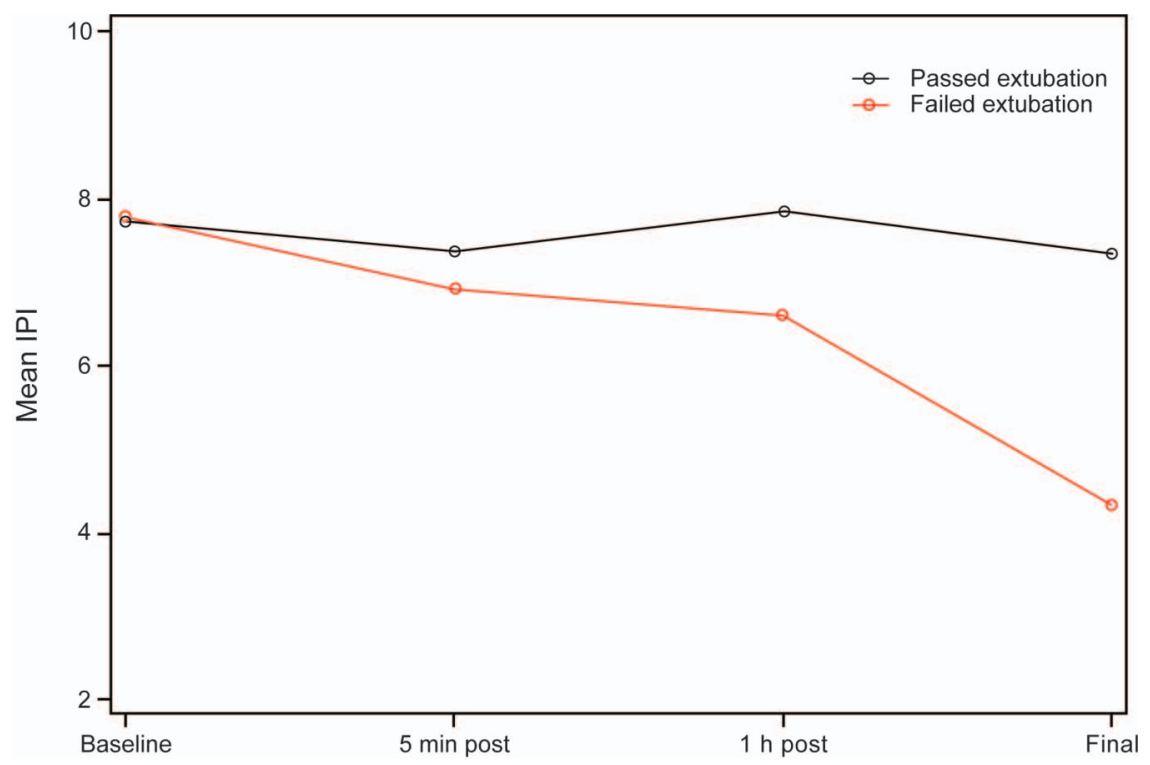

Fig. 2. Observed integrated pulmonary index (IPI) before and after extubation.

Table 2. Mixed-Effects Regression Model Results for Integrated Pulmonary Index Over Time

\begin{tabular}{lcr}
\hline \multicolumn{1}{c}{ Group } & Estimate $\pm \mathrm{SE}$ & \multicolumn{1}{c}{$P$} \\
\hline Extubation success group & $7.73 \pm 0.28$ & \\
$\quad$ Baseline & $7.38 \pm 0.30$ & $.12^{*}$ \\
5 min after & $7.79 \pm 0.28$ & $.76^{*}$ \\
1 h after & $7.33 \pm 0.37$ & $.26^{*}$ \\
Last IPI & $0.05 \pm 0.58$ & .93 \\
Group difference: failure - success & $-0.44 \pm 0.63$ & .48 \\
Baseline & $-1.19 \pm 0.58$ & .044 \\
5 min after & $-3.03 \pm 0.80$ & $<.001$ \\
1 h after & & \\
Last IPI & & \\
& & \\
* $P$ values for comparisons relative to baseline in success group; other $P$ values are for group \\
comparisons. \\
IPI = integrated pulmonary index
\end{tabular}

tion outcome. Since most subjects had an IPI that decreased over time, these results also mean that decreases in the third and last IPI measurements increased the odds of having a failed extubation outcome. Specifically, a 1-unit decrease in IPI3-1 change increased the odds of failure to 1.57 times (95\% CI 1.01-2.45). A 1 -unit decrease in the IPI $4-1$ change increased the odds of failure to 1.72 times (95\% CI $1.26-2.34)$. We also found that both IPI $3-1$ and IPI $4-1$ are statistically correlated (correlation coefficient $=0.23$, $P=.08)$. Therefore, due to the clinical importance of the timing of the third IPI measure, the change in IPI $1 \mathrm{~h}$ after extubation can be considered as an optimal predictor for the extubation outcome.

\section{Discussion}

This study assessed the association between IPI and extubation outcome. After extubation, the mean IPI value remained stable among subjects who were successfully extubated; however, the mean IPI value decreased over time among those who failed extubation. Both the decline in IPI after $1 \mathrm{~h}$ and last IPI recorded after extubation are predictive of extubation failure. Although the change in last IPI from baseline has a stronger association, the earlier timing in change of IPI $1 \mathrm{~h}$ after extubation is of more clinical value as a predictor of extubation failure. The earlier prediction of extubation failure would allow for use of clinical interventions that may prevent these patients from progressing to respiratory failure.

An extubation failure rate of $10-20 \%$ is common. ${ }^{2}$ If patients require re-intubation, they are more likely to have poor clinical outcomes and a high mortality rate. ${ }^{2,4} \mathrm{Re}$ searchers have demonstrated that patients requiring re-intubation due to upper-airway issues have a lower mortality rate as compared with those with non-airway issues like respiratory failure and congestive heart failure. ${ }^{4,6}$ They suggested that instruments should be developed to identify patients who are at risk of deterioration and extubation failure. Currently, bedside clinicians rely on individual vital signs (heart rate, breathing frequency, and $\mathrm{S}_{\mathrm{pO}_{2}}$ ) to assess the extubation outcome and alert the medical team of any impending signs of respiratory failure.

Dead space fraction has been shown to be a powerful predictor of extubation success in the adult population. ${ }^{11}$ But calculation of dead space fraction, $\left(\mathrm{P}_{\mathrm{aCO}_{2}}-\mathrm{P}_{\mathrm{ETCO}_{2}}\right) / \mathrm{P}_{\mathrm{aCO}}$, requires invasive arterial blood sampling and measurement of mean exhaled $\mathrm{CO}_{2}$. These requirements limit its 
Table 3. Logistic Regression Model Predicting Extubation Success

\begin{tabular}{|c|c|c|c|c|}
\hline Parameters & Estimate $\pm \mathrm{SE}$ & $P$ & OR & $95 \%$ CI for OR \\
\hline \multicolumn{5}{|c|}{ IPI 1-h change from baseline (IPI3 -1 ) as predictor } \\
\hline African American & $-1.18 \pm 0.70$ & .09 & 0.31 & $0.08-1.21$ \\
\hline IPI3 - 1 & $0.45 \pm 0.23$ & .049 & 1.57 & $1.01-2.45$ \\
\hline \multicolumn{5}{|c|}{ Last IPI change from baseline (IPI4 -1 ) as predictor } \\
\hline African American & $-1.60 \pm 0.83$ & .054 & 0.20 & $0.04-1.03$ \\
\hline IPI $4-1$ & $0.54 \pm 0.16$ & $<.001$ & 1.72 & $1.26-2.34$ \\
\hline
\end{tabular}

use in critical care units to monitor respiratory status of patients postextubation. Although $\mathrm{P}_{\mathrm{ETCO}}$ has a well-established role in detecting sedation-related respiratory depression, ${ }^{12}$ there is very limited literature available on its utility to predict extubation outcome in adults. Research studies in a pediatric population have shown that higher $\mathrm{P}_{\mathrm{ETCO}_{2}}$ value is associated with failed extubation outcome. ${ }^{13}$ The IPI algorithm includes $\mathrm{P}_{\mathrm{ETCO}_{2}}$ measurement in its calculation and hence provides a noninvasive method to monitor ventilation status in patients postextubation.

In our study, we found that a declining IPI value was an early indicator of extubation failure. IPI encompasses several variables $\left(\mathrm{P}_{\mathrm{ETCO}_{2}}\right.$, heart rate, breathing frequency, and $\mathrm{S}_{\mathrm{pO}_{2}}$ ) into one parameter that may improve clinicians' ability to recognize patients with respiratory compromise sooner by monitoring trends in a single variable rather than 4 separate variables. Recognition of this downward trend in IPI may allow for application of timely interventions to lessen the clinical deterioration and may prevent re-intubation.

Several interventions are available to manage postextubation respiratory failure. High-flow nasal oxygen has been shown to reduce the risk of re-intubation among low risk patients. ${ }^{14}$ Although the role of early NIV to prevent reintubation in patients who develop respiratory failure after extubation is controversial, ${ }^{15}$ a recent study by Thille et a ${ }^{16}$ demonstrated that prophylactic use of noninvasive ventilation after extubation may decrease the re-intubation rate in patients with easily identified risk factors. Furthermore, in a randomized clinical trial among high-risk subjects, Hernández et a ${ }^{17}$ showed that the use of high-flow oxygen therapy was similar to NIV in terms of preventing reintubation and postextubation respiratory failure. However, delay in re-intubation and reinstituting ventilatory support has proven to be associated with increased mortality in patients with extubation failure. ${ }^{4,18} \mathrm{We}$ believe that continuous respiratory monitoring with IPI can prevent delay in detecting postextubation respiratory failure, and therefore it may allow for timely application of appropriate therapies that can improve the adverse effects associated with extubation failure.
After adjusting for sex, age, body mass index, duration of mechanical ventilation, and reason for mechanical ventilation, African-American subjects were less likely to be successfully extubated than the rest of the population. There are very limited data available to support this finding, but a study published in 2011 by Erickson et al ${ }^{19}$ demonstrated that African-Americans had a higher acute physiology score at the time of ICU admission and had a longer unadjusted length of ICU stay. It may be that these acute physiologic derangements at the time of ICU admission influence the extubation outcome in the African-American population and require further study.

This study has some limitations. First, this was an observational study, and hence no intervention was made based on the IPI value. This was the first study conducted to examine the role of IPI in identifying extubation outcome. Although there is no literature available to assess the reliability of IPI value in extubated patients, we propose that this method can be easily reproduced as IPI becomes commercially available in patient-monitoring devices. Second, 26 of the 84 extubated subjects were lost due to technical issues, which further limited the data available for analysis, but subject characteristics included in both groups were similar, and the primary outcome reached significance. Furthermore, the population enrolled in this study was heterogeneous in nature in terms of reason for intubation and length of mechanical ventilation, and the purpose of this was to ensure that we identified the role of IPI in a heterogeneous population. Last, patients who failed $>3$ SBTs were excluded from this study, which may cause uncertainty in establishing the role of IPI monitoring in difficult-to-wean patients.

\section{Conclusions}

In this prospective study, we observed that declining IPI measurements over time are predictive of extubation failure in postextubation subjects. Further studies are needed to determine the role of IPI in guiding interventions that may prevent extubation failure. 


\section{IDENTIFYING EXTUBATION FAILURE WITH IPI}

\section{ACKNOWLEDGMENTS}

We gratefully acknowledge the contributions of Meagan Dubosky MSc RRT, Kyle Jendral MSc RRT, and Toni Podgorak MSc RRT to study design, data collection, and equipment maintenance. We thank Sharon Foley PhD RDN LDN for assistance with statistical analysis. We also acknowledge the support of all of the staff from Respiratory Care Services at Rush University Medical Center for assistance with data collection and equipment maintenance.

\section{REFERENCES}

1. Epstein SK, Ciubotaru RL, Wong JB. Effect of failed extubation on the outcome of mechanical ventilation. Chest 1997;112(1):186-192.

2. Thille AW, Richard JC, Brochard L. The decision to extubate in the intensive care unit. Am J Respir Crit Care Med 2013;187(12):12941302.

3. Eskandar N, Apostolakos MJ. Weaning from mechanical ventilation. Crit Care Clin 2007;23(2):263-274, x.

4. Epstein SK, Ciubotaru RL. Independent effects of etiology of failure and time to reintubation on outcome for patients failing extubation. Am J Respir Crit Care Med 1998;158(2):489-493.

5. Esteban A, Frutos F, Tobin MJ, Alía I, Solsona JF, Valverdú I, et al. A comparison of four methods of weaning patients from mechanical ventilation: Spanish Lung Failure Collaborative Group. N Engl J Med 1995;332(6):345-350.

6. Esteban A, Alía I, Gordo F, Fernández R, Solsona JF, Vallverdú I, et al. Extubation outcome after spontaneous breathing trials with Ttube or pressure support ventilation: The Spanish Lung Failure Collaborative Group. Am J Respir Crit Care Med 1997;156(2 Pt 1):459465.

7. Vallverdú I, Calaf N, Subirana M, Net A, Benito S, Mancebo J. Clinical characteristics, respiratory functional parameters, and outcome of a two-hour T-piece trial in patients weaning from mechanical ventilation. Am J Respir Crit Care Med 1998;158(6):1855-1862.

8. Kulkarni AP, Agarwal V. Extubation failure in intensive care unit: predictors and management. Indian J Crit Care Med 2008;12(1):1-9.

9. Lee KH, Hui KP, Chan TB, Tan WC, Lim TK. Rapid shallow breathing (frequency-tidal volume ratio) did not predict extubation outcome. Chest 1994;105(2):540-543.
10. Ronen M, Weissbrod R, Overdyk FJ, Ajizian S. Smart respiratory monitoring: clinical development and validation of the IPI (Integrated Pulmonary Index) algorithm. J Clin Monit Comput 2017; 31(2):435-442.

11. González-Castro A, Suárez-Lopez V, Gómez-Marcos V, GonzálezFernandez C, Iglesias-Posadilla D, Burón-Mediavilla J, et al. Utility of the dead space fraction $(\mathrm{Vd} / \mathrm{Vt})$ as a predictor of extubation success. Med Intensiva 2011;35(9):529-538.

12. Waugh JB, Epps CA, Khodneva YA. Capnography enhances surveillance of respiratory events during procedural sedation: a metaanalysis. J Clin Anesth 2011;23(3):189-196.

13. Rasera CC, Gewehr PM, Domingues AM. PET $\left(\mathrm{CO}_{2}\right)$ measurement and feature extraction of capnogram signals for extubation outcomes from mechanical ventilation. Physiol Meas 2015;36(2):231-242.

14. Hernández G, Vaquero C, González P, Subira C, Frutos-Vivar F, Rialp G, et al. Effect of postextubation high-flow nasal cannula vs conventional oxygen therapy on reintubation in low-risk patients: a randomized clinical trial. JAMA 2016;315(13):1354-1361.

15. Esteban A, Frutos-Vivar F, Ferguson ND, Arabi Y, Apezteguía C, González M, et al. Noninvasive positive-pressure ventilation for respiratory failure after extubation. N Engl J Med 2004;350(24):24522460.

16. Thille AW, Boissier F, Ben-Ghezala H, Razazi K, Mekontso-Dessap A, Brun-Buisson C, Brochard L. Easily identified at-risk patients for extubation failure may benefit from noninvasive ventilation: a prospective before-after study. Crit Care 2016;20:48.

17. Hernández G, Vaquero C, Colinas L, Cuena R, González P, Canabal A, et al. Effect of postextubation high-flow nasal cannula vs noninvasive ventilation on reintubation and postextubation respiratory failure in high-risk patients: a randomized clinical trial. JAMA 2016; 316(15):1565-1574.

18. Esteban A, Alía I, Tobin MJ, Gil A, Gordo F, Vallverdú I, et al Effect of spontaneous breathing trial duration on outcome of attempts to discontinue mechanical ventilation: Spanish Lung Failure Collaborative Group. Am J Respir Crit Care Med 1999;159(2):512518 .

19. Erickson SE, Vasilevskis EE, Kuzniewicz MW, Cason BA, Lane RK, Dean ML, et al. The effect of race and ethnicity on outcomes among patients in the intensive care unit: a comprehensive study involving socioeconomic status and resuscitation preferences. Crit Care Med 2011;39(3):429-435. 